Research Article

\title{
The Last Mile: Safety Management Implementation in Construction Sites
}

\author{
Tingshen Zhao, Seyed Ebrahim Kazemi $(\mathbb{D}$, Wen Liu $\mathbb{D}$, and Miao Zhang $\mathbb{D}$ \\ School of Civil Engineering \& Mechanics, Huazhong University of Science and Technology, Wuhan, China \\ Correspondence should be addressed to Miao Zhang; 1224501618@qq.com
}

Received 21 December 2017; Revised 17 February 2018; Accepted 21 March 2018; Published 18 April 2018

Academic Editor: Yingbin Feng

Copyright (c) 2018 Tingshen Zhao et al. This is an open access article distributed under the Creative Commons Attribution License, which permits unrestricted use, distribution, and reproduction in any medium, provided the original work is properly cited.

To deepen the understanding of the construction safety accidents rules as well as identify and cure the crux of construction safety management failures in China, we analyzed the status quo of safety management and identified the "last mile" problem, that is, the failure of implementation of the extensive legal and regulatory systems on the construction site. The safety factors were then extracted based on a questionnaire consisting of 34 items. Through factor analysis and ranking correlation, five human factors were found to be the greatest challenge and leverage point of safety management at construction sites. Accordingly, a novel safety management framework was proposed and tested as part of the Wuhan-Shenzhen highway project. Expert auditing confirmed that the proposed framework could substantially improve the construction safety performance and thus bridge the "last mile" of safety management implementation.

\section{Introduction}

As has been shown in different countries around the world, construction is among the most unsafe industries because of its unique nature $[1,2]$. Nowadays, projects are carried out at an increasing rate and complexity, and accidents are leading to greater repercussions $[3,4]$. Regrettably, the booming construction industry has always been accompanied by many accidents and deaths, which is especially true in developing countries like China. The mortality rate in the Chinese construction industry has long sustained unacceptably high numbers, contributing to tremendous monetary losses as well [5].

Many countries have implemented laws and regulations to strengthen safety management in their construction industry, most importantly to prevent accidents and reduce deaths [6, 7]. In China, the Production Safety Law [8] was promulgated in 2002, specifying how safety should be guaranteed, how employees should meet their obligations and exercise their rights, how safety should be supervised and administered, and how accidents should be handled. In 2004, the Administrative Regulations on the Work Safety of Construction Projects [9] took effect, which further defined and divided the liabilities among various entities in charge of construction, survey, design, and supervision. The national standard GB/T 28001-2011 on the "occupational health and safety management system" [10] was issued in 2012. Over the past decades, China has gradually built a systematic safety management standard and introduced appropriate laws. In China, the accident level is divided into minimal, moderate, high, and disastrous listing based on economic losses and number of deaths and serious injuries reported. The project manager is required to contact and report to the local safety supervision department within 1 hour of the accident. Based on the severity of the accident, the local or higher government will then setup a professional team to investigate the cause of the accident. Concealment and omission of the accident are becoming more and more difficult and costly because of the sound and rigorous legal and media supervision. The bureau of statistics has reported that the annual construction accidents from all projects throughout China have declined from 1193 in 2005 to 554 in 2015, which gratifyingly shows a decreasing trend (Figure 1).

Though the number of construction accidents is decreasing, statistics also show that the average death per accident has stayed largely consistent at 1.24 over the past 


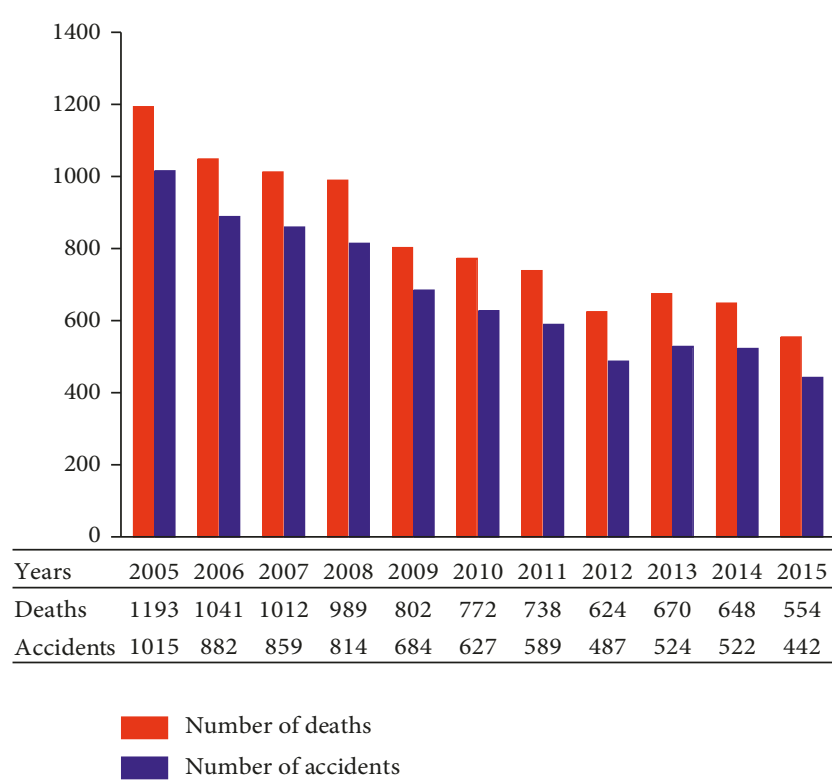

FIGURE 1: The number of accidents and deaths in the construction industry in China (2005-2015).

decades (Figure 1). This unveils some persisting issues, despite the encouraging decline in the number of accidents. We see this as a typical "last mile" problem and ascribe it to the gap between the actual safety practice on site and the existing laws, regulations, standards, and systems of safety management. Specifically, safety management and supervision systems have been well devised at all levels, from the government to construction companies and further down to project groups. However, without a mechanism for self-adjustment in each project, the constantly changing situations on site, as well as human error, can prevent the externally designed safety management systems from working. Accidents result from operations violating safety rules that are carried out to deal with an unexpected and temporary concern. Here, we find the "last mile" problem-the failure to implement extensive legal and regulatory systems on construction sites.

To overcome this problem and improve the construction safety management performance, we intend to find the leverage points of safety management implementation, defined as "places within a complex system (a corporation, an economy, a living body, a city, and an ecosystem) where a small shift in one thing can produce big changes in everything" [11]. Further, the corresponding prevention and control measures are designed to work on these leverage points, thus bridging the last mile. The remainder of the paper is organized as follows: in Section 2, we provide an extensive literature review on construction safety measures in several countries and we introduce a theoretical framework with possible influencing factors. Section 3 presents our methodology, including the design and response of our questionnaire. Section 4 analyzes the safety management at construction sites, identifies the main challenges, and discusses the leverage points. Section 5 presents a case study that adopted the recommendations derived from the leverage points and the subsequent improvement in project safety. Conclusions are drawn in Section 6.

\section{Literature Review}

Factors that influence safety management at construction sites have been previously categorized into macro-, meso-, and microlevels, corresponding to sector/country factors, organizational factors, and human factors, respectively [12]. A similar classification [13] was applied to aggregate variables in the system of Occupational Safety and Health $(\mathrm{OSH})$. In this work, we adopt an eventual division of factors into macro-, meso-, and microlevels.

2.1. Macrolevel Factors. In any developed country, safety is a crucial issue in the construction industry. Safety legislation and policies have been developed around the globe over the past decades (Table 1 for selected examples), having a great impact on the construction site safety. These legislations regulate and control health and safety on the macrolevel [14].

Furthermore, national safety management systems have been devised and adopted in many countries on the basis of appropriate standard practices. Depending on the specific requirements, these systems differ among countries with regard to the factors considered. For example, Wokutch and VanSandt extracted 8 key factors as the main frameworks of OHS management in the United States [15]. Fang et al. discussed empirical research done on workplace safety management performance on construction sites in China. Eleven factors that correlate closely with onsite safety management performance were identified to establish national safety management systems [16]. Teo and Ling discussed the safety management system (SMS) which had been applied to the construction industry for about 10 years in Singapore, though the improvement in safety standard is not significant. In response to the need to improve the effectiveness of the SMS and SMS audit, they divided 14 main safety management elements in SMS [17]. Ismail et al. compared the safety management system (SMS) adopted by various countries around the world and then identified the factors influencing the implementation of a safety management system for construction sites in Malaysia [7]. By reviewing and summarizing the research results of different scholars on the composition of their own SMS system, Table 2 provides a summary of the macrolevel safety factors included in the safety management systems [14-20].

2.2. Mesolevel Factors. Construction companies have diverse safety cultures, safety climates, working conditions, and habits [21]. These company factors reside on the mesolevel. The Post-Accident Review Meeting on the Chernobyl Accident by the International Atomic Energy Agency (IAEA, 1986) for the first time established the term "safety culture," including it in INSAG's Summary Report. Safety culture involves the values, beliefs, and attitudes shared within a group [22]. Choudhry et al. [23] reviewed safety culture, examined its definition, empirical evidence, and theoretical development, and proposed how to systematically analyze safety culture. The analysis recognized elements in the organizational, situational, technical, and human aspects, as well as interactions between these elements. Chinda [24] delved deeper into the 
TABLE 1: Laws and regulations of various countries on safe production.

\begin{tabular}{lcc}
\hline Country & Effective since & Title \\
\hline UK & January 1974 & $\begin{array}{c}\text { The Health and Safety at Work } \\
\text { Construction (Design and } \\
\text { Management) Regulations 2015 }\end{array}$ \\
\hline USA & September 1970 & $\begin{array}{c}\text { Occupational Safety and Health } \\
\text { Act }\end{array}$ \\
& February 1926 & Part 1926 of the OSHA standards \\
Singapore & January 1948 & $\begin{array}{c}\text { The Factories Act (Chapter 104) } \\
\text { Singapore Code of Practice on } \\
\text { Construction Safety } \\
\text { Management System }\end{array}$ \\
& 1994 1999 & $\begin{array}{c}\text { Building Operations and Works } \\
\text { of Engineering Construction }\end{array}$ \\
China & November 2002 & $\begin{array}{c}\text { Production Safety Law of the } \\
\text { People's Republic of China } \\
\text { Administrative Regulations on } \\
\text { the Work Safety of Construction } \\
\text { Project }\end{array}$ \\
\hline Hong Kong & June 1997 1997 & $\begin{array}{c}\text { Factories and Industrial } \\
\text { Undertaking Ordinances } \\
\text { Occupational Safety and Health } \\
\text { Ordinances }\end{array}$ \\
\hline & June 2004 &
\end{tabular}

interactions between the key elements of construction safety culture, enablers, and goals, and within the enablers themselves. Molenaar et al. [25] characterized five latent variables to describe safety culture in a company. Gilkey et al. [26] evaluated the risk perception, safety culture, and safety climate in a residential construction project at Denver, Colorado.

The term "safety climate" was coined by Zohar [27] in studying safety attitudes in Israeli manufacturing. In contrast to safety culture, it refers to how the employees collectively perceive the organization's practices, procedures, and policies, as well as how they value safety in the organization [28-31]. It is often regarded as a key indicator of improving workplace safety [32]. Statistically significant correlations were found between safety climate and personal characteristics, such as education level, marital status, gender, direct employer, and drinking habits [33]. Lin et al. [34] found three key factors for successful safety climates: safety awareness, safety competence, and safety communication. Choudhry et al. [35] identified ten dimensions of a successful safety climate, such as competence, risk-taking behavior, safety resources, and improper safety procedure. Stoilkovska et al. [36] incorporated three facets into their measure of safety climates: (1) management commitment, (2) workers' commitment, and (3) safety inspections and perceived accident rate. The model of Liao et al. [37] comprised seven dimensions, such as supportive environment, supervisory environment, work pressure, and personal appreciation of risk.

The safety climate and safety culture are related independent concepts despite of their similarity in definition to some extent [38]. Safety climate can be considered a "snapshot" of safety culture [39]. In other words, the safety culture acts behind safety climate [40], and the latter is the manifestation of the former [41]. Nevertheless, both of them are closely related to the safety management of the construction enterprises and should be given high priority.

2.3. Microlevel Factors. The human factor in construction accidents has been explored extensively. It is commonly acknowledged that unsafe behavior underlies workplace accidents [42] and worker behavior must be proactively managed. Choudhry and Fang [6] conducted a series of interviews within the Hong Kong construction industry to determine reasons for unsafe behaviors. Their findings included disinterest in safety, failure to obey procedures, and lack of safety knowledge. Specifically, disinterest in safety was characterized by failure to identify unsafe conditions, lack of skill or training, unsafe work conditions, and not wearing personal protective equipment (PPE). Using the Bayesian network theory, Zhou et al. [43] quantified the links among five safety climate factors and four personal experience factors. They then used the survey data from Gammon Construction Limited and assessed, using their methodology, whether candidate strategies can improve safety behavior. Saurin and de Macedo Guimaraes [44] examined the workers' perceptions on scaffolding safety and determined that poor and stressful working conditions resulted from the combination of uncomfortable work posture, failures in safety planning and control, inappropriate inspections, and inadequate PPE use. Zheng et al. [45] suggested that, in central China, nonfatal construction injuries are high throughout the year, and the major risk factors for which were found to include the lack of injury prevention and safety education, serious cigarette smoking and/or alcohol consumption, and depressive symptoms. Jitwasinkul and Hadikusumo [46] identified seven important factors that affect safe behaviors in the construction industry of Thailand. Leung et al. [47] and Hung et al. [48] argued that construction workers' ill-formed safety attitudes can give rise to safety issues and risky behaviors.

Chi et al. [49] emphasized supervision, PPE and safety devices, safety training, and proper site inspections. Mattila and Hyttinen [50] and Teo et al. [51] contended that the project manager should vigilantly monitor personnel behavior and rectify problems. They noted a few important process variables and also noted several personnel variables.

2.4. The Last Mile. On each level, factors have been analyzed by many researchers and solutions have been proposed. The safety production-related laws and regulations of construction industries in China and the system framework for construction enterprise safety management have gradually improved over the past few decades. These laws and regulations are to some extent mandatory. Nevertheless, there are always a few workers intentionally or unintentionally violating the laws and regulations because of their subjective initiatives responding to volatile environment. In other words, the proposals on the macro- and mesolevels cannot be effectively implemented on the construction site because of human factors. Therefore, how to translate these good proposals into emotional recognition and conscious action of every worker on the construction site is the key to 
TABLE 2: Safety factors included in safety management systems adopted by some countries.

\begin{tabular}{|c|c|c|c|c|c|c|c|c|c|c|}
\hline Safety factor & Australia & China & Finland & Jordan & Malaysia & Netherland & Singapore & Spain & Thailand & USA \\
\hline Safety meeting & & $\checkmark$ & & $\checkmark$ & & & & & & $\checkmark$ \\
\hline Safety inspection & $\checkmark$ & $\checkmark$ & & $\checkmark$ & & & & & $\checkmark$ & $\checkmark$ \\
\hline Safety regulation enforcement & & $\checkmark$ & & & $\checkmark$ & $\checkmark$ & & & $\checkmark$ & $\checkmark$ \\
\hline Safety training & $\checkmark$ & $\checkmark$ & $\checkmark$ & $\checkmark$ & $\checkmark$ & $\checkmark$ & & $\checkmark$ & $\checkmark$ & $\checkmark$ \\
\hline Safety communication & & $\checkmark$ & & & $\checkmark$ & & & $\checkmark$ & $\checkmark$ & $\checkmark$ \\
\hline Safety cooperation & & $\checkmark$ & & & & & & & & $\checkmark$ \\
\hline Management worker relationship & & $\checkmark$ & & & & & $\checkmark$ & & & $\checkmark$ \\
\hline Safety resources & & $\checkmark$ & & & & & & & $\checkmark$ & $\checkmark$ \\
\hline Personal competency & & & $\checkmark$ & & & & & & $\checkmark$ & \\
\hline Personal motivation & & & & $\checkmark$ & $\checkmark$ & & & & $\checkmark$ & \\
\hline Equipment management & $\checkmark$ & & & $\checkmark$ & & & & & $\checkmark$ & \\
\hline Program evaluation & & & & & & & & & $\checkmark$ & \\
\hline Management commitment & & & & & $\checkmark$ & & $\checkmark$ & & $\checkmark$ & \\
\hline Authority and responsibility & & & $\checkmark$ & & $\checkmark$ & $\checkmark$ & & & $\checkmark$ & \\
\hline Prevention planning & & & & & & & & $\checkmark$ & & \\
\hline Emergency planning & $\checkmark$ & & & & & & & $\checkmark$ & & \\
\hline Safety controlling & $\checkmark$ & & & & $\checkmark$ & & & $\checkmark$ & & \\
\hline Benchmarking & & & & & & & & $\checkmark$ & & \\
\hline $\begin{array}{l}\text { Incentive and punishment and } \\
\text { recognition }\end{array}$ & $\checkmark$ & & & & & & $\checkmark$ & $\checkmark$ & & \\
\hline Safety policy and statutory requirement & & & & $\checkmark$ & & & $\checkmark$ & $\checkmark$ & & \\
\hline $\begin{array}{l}\text { Management difficulty and } \\
\text { subcontractors }\end{array}$ & & & & & $\checkmark$ & & $\checkmark$ & & & \\
\hline Safety attitude & & & & $\checkmark$ & & & $\checkmark$ & & & \\
\hline Safety analysis & $\checkmark$ & & & & & $\checkmark$ & & & & \\
\hline Safety organization & & & & & $\checkmark$ & $\checkmark$ & & & & \\
\hline Thematic approach & & & & & & $\checkmark$ & & & & \\
\hline Clear goals & & & $\checkmark$ & & $\checkmark$ & & & & $\checkmark$ & \\
\hline Availability & & & & & $\checkmark$ & & & & & \\
\hline Construction cost optimization & & & & & $\checkmark$ & & & & & \\
\hline Labor turnover rate & & & & $\checkmark$ & & & & & & \\
\hline Work involvement & & & $\checkmark$ & & & & & & & \\
\hline Management support & $\checkmark$ & & $\checkmark$ & & & & & & & \\
\hline Safety review & $\checkmark$ & & & & & & & & & \\
\hline
\end{tabular}

bridging the "last mile." In this work, instead of focusing on a single entity, we try to collect the views and opinions of every entity on construction sites and propose a new framework to tackle the "last mile" problem through an integrated analysis.

\section{Methodology and Results}

The research methodology is shown in Figure 2. The first step was to review the safety factors on each individual level and identify the "last mile" problem.

In step 2, relevant attributes were selected and collated based on the literature review, exploratory interviews (step 3), and the pilot study (step 4). A questionnaire was then designed to survey practitioners' perceptions of the importance of the collated attributes (step 5).

Data collected from the questionnaire was analyzed (step 6) to give five factors that are significantly related to the construction safety (step 7) and the weights of these factors (step 8). It was found that the items related to workers are the key leverage points (step 9), and a new framework for safety management was proposed accordingly (step 10).
A rating method was then developed (step 11) and verified by ten industry experts. Thereafter, the new framework for safety management was tested through two site audits. The feedback shows that the safety management on construction sites improved considerably. The results confirmed that the new framework could solve the "last mile" problem (step 12).

3.1. Questionnaire Design. Data on the views of various entities in construction projects were collected through a questionnaire to enable an objective and cost-effective investigation. First, a comprehensive list of safety factors was screened in a pilot study to ensure that all items in the questionnaire were valid, reliable, and significant. Then, item analysis was administered to see if an item itself could separate a participant from the rest. The results indicated that all items gave $p<0.05$ and were thus significant. Zero was excluded from the $95 \%$ confidence interval of the difference.

Based on exploratory interviews and the above pilot study, we composed a questionnaire and solicited responses from several ongoing construction projects throughout China. The questionnaire contained two sections. The first section collected the general information of the respondents, 


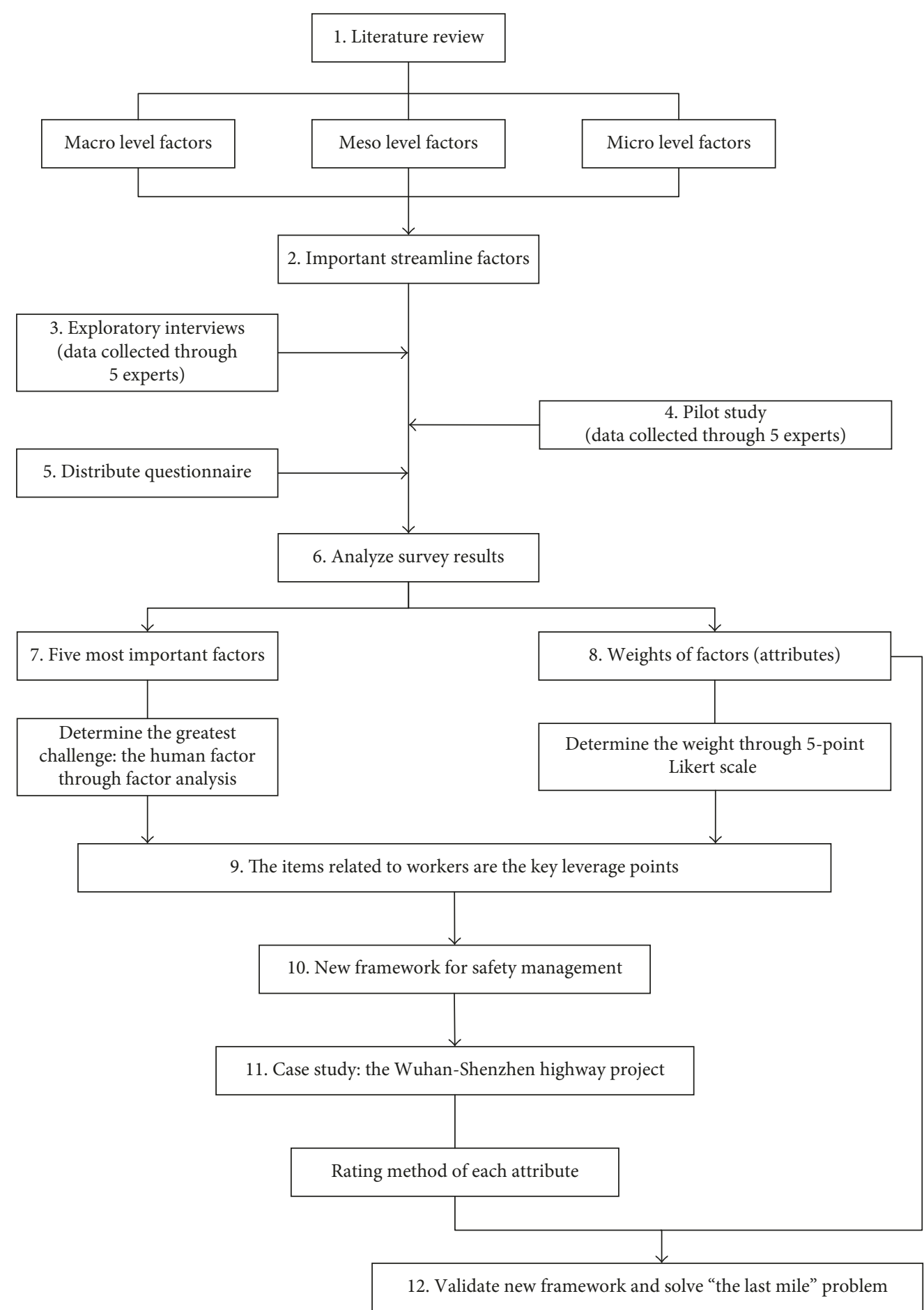

FIgURE 2: Research methodology.

and the second section consisted of 34 factors (listed in Table 3 ) that could potentially affect the safety management at construction sites. All items adopted a Likert-type scale for the answers, ranging from a value of 1 (not important) to 5 (extremely important).

3.2. Questionnaire Respondents. Responses were solicited from various entities at eight construction sites in three typically large projects under construction in central and eastern China, including proprietors, consultants, designers, contractors, and supervisors. Five of the eight construction sites are located in Wuhan section of the Wuhan-Shenzhen highway project, two of them are located in the Guandu Yellow River Bridge project, and the last one is located in the Wufeng Mountain Yangtze River Bridge project. The questionnaire survey was carried out in a voluntary and anonymous manner with the strong support and coordination of 
TABle 3: Questionnaire items.

\begin{tabular}{|c|c|}
\hline Item & Key items \\
\hline 1 & Safety attitude of workers \\
\hline 2 & Safety behavior of workers \\
\hline 3 & Safety training received by workers \\
\hline 4 & The health and safety file \\
\hline 5 & Safety meeting \\
\hline 6 & Experience and skills of workers \\
\hline 7 & Education level of workers \\
\hline 8 & Personal protective equipment \\
\hline 9 & Safety management commitment \\
\hline 10 & $\begin{array}{c}\text { Safety experience and skills of contractors and } \\
\text { supervisors }\end{array}$ \\
\hline 11 & Safety attitude of contractors and supervisors \\
\hline 12 & $\begin{array}{c}\text { Safety education and knowledge of contractors and } \\
\text { supervisors }\end{array}$ \\
\hline 13 & $\begin{array}{c}\text { Proper installation and dismantling of plant and } \\
\text { equipment }\end{array}$ \\
\hline 14 & Maintenance regime for all equipment and plants \\
\hline 15 & The reasonable choice of work equipment \\
\hline 16 & Proper handling of all equipment and plants \\
\hline 17 & Safety regulation and plan enforcement \\
\hline 18 & Safety incentive and punishment \\
\hline 19 & Safety risk identification and analysis \\
\hline 20 & First aid and emergency preparedness \\
\hline 21 & Safety inspection and guidance \\
\hline 22 & Complexity of geology and hydrology \\
\hline 23 & Frequency of adverse weather \\
\hline 24 & Schedule and cost pressures \\
\hline 25 & Allocation of safety responsibility \\
\hline 26 & Effective communication and cooperation \\
\hline 27 & Organizational capability of contractors \\
\hline 28 & Evaluation, selection, and control of subcontractors \\
\hline 29 & The complexity type and technique of construction \\
\hline 30 & Quantity of workers on the construction site \\
\hline 31 & Mobility of workers on the construction site \\
\hline 32 & Complexity of surrounding environment \\
\hline 33 & Welfare facilities \\
\hline 34 & The numbers of modifying existing designs \\
\hline
\end{tabular}

the project owners. In total, 513 questionnaires were distributed and 447 valid questionnaires were retrieved, thus giving an effective recovery rate of $87.13 \%$. The $12.87 \%$ invalid questionnaires were either incompletely answered or declined by the respondent to participate. Figure 3 shows the breakdown of the respondents of the 447 valid questionnaires in terms of age, years of work experience in construction, education level, and job duties.

The construction industry has advanced rapidly in China. As a result, the role of the project manager has been increasingly assumed by fresh graduates, where construction workers mostly come from rural areas and where education is poor. Inadequate experience is common among the personnel at project sites. Statistics in Figure 3 show that 39\% of the respondents were $20-30$ years old, $39.6 \%$ had $1-5$ years of working experience in the construction industry, and $71 \%$ finished their education at, or below, the high school level. A further breakdown on the hierarchy of job duties shows that among the 447 respondents, senior managers accounted for $4.5 \%$, middle managers for $24.3 \%$, front-line managers for $38.2 \%$, and workers for $33.0 \%$.
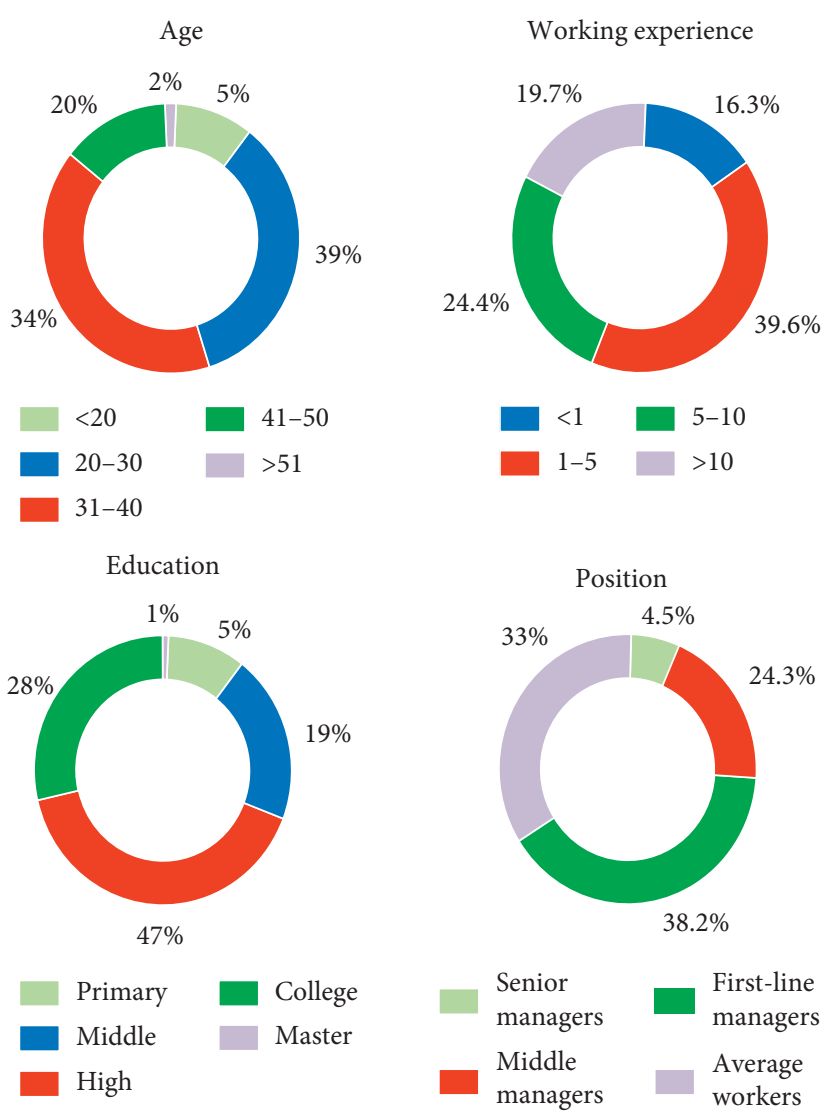

FIGURE 3: Segmentation in various dimensions of the 477 valid respondents.

3.3. Statistical Analysis. Collected data were analyzed with the Statistical Package for Social Science (SPSS 18.0) using the following techniques: (1) factor analysis, (2) estimation of mean value, (3) rank cases, (4) one-way analysis of variance (ANOVA), and (5) Spearman rank correlation.

Factor analysis relies on a set of common underlying dimensions, known as factors, to unveil the correlations among a large number of variables [16, 52-54]. The current analysis identified the major challenges in implementing the macro- and mesolevel management and supervision system during the day-to-day practices. Different participants assign different weights to the safety factors, and inspecting the discrepancy in their ranking can help to determine the leverage points in dealing with the challenges in safety management at construction sites, thus closing the "last mile." The current results have a high level of significance at $p<0.01$, compared with the more commonly seen significance level of 0.05 .

3.4. Five Significant Related Factors. Data were first checked with the KMO and Bartlett's tests in SPSS. Table 4 shows that the KMO test gives a result of 0.795 , which has passed the cutoff of 0.5 , and confirms that the items in the questionnaire have enough factors in common to allow for factor analysis. The approximate chi-square distribution is 1600.223 and arrives at the significance level $p \leq 0.001$ when the degree of 
TABLE 4: KMO and Bartlett tests.

Kaiser-Meyer-Olkin metric for sampling sufficient degree 0.795

\begin{tabular}{ccc}
\hline & Approximate chi square & 1600.223 \\
Bartlett test of sphericity & d.f. & 561 \\
& $p$ & 0.000 \\
\hline
\end{tabular}

freedom is 561 . The overall correlation matrix is thus not an identity matrix, and the factor analysis is valid.

The load factor refers to the correlation between variables in a factor. A factor can be synthesized by a number of variables in that after varimax rotation, principal component analysis gives a relatively high load factor between the derived variables. Variables are consolidated into common factors when possible, which then clarifies what these factors represent. Table 5 shows the resulting key safety factor dimensions, based on outlining the five challenges that are significantly related to construction safety as follows.

3.4.1. Challenge 1: Human Factor. This principal factor accounts for $32.986 \%$ of the total variance and exists in the following items:

(1) Safety attitude of workers

(2) Safety behavior of workers

(3) Safety training received by workers

(6) Experience and skills of workers

(7) Education level of workers

(10) Safety experience and skills of contractors and supervisors

(11) Safety attitude of contractors and supervisors

(12) Safety education and knowledge of contractors and supervisors

(26) Effective communication and cooperation

(30) Quantity of workers on construction sites

(31) Mobility of workers on construction sites

Among the abovementioned items, 1, 2, 3, 6, 7, 26, 30, and 31 can be attributed to the workers and items 10, 11, and 12 to the managers at the project sites. Thus, Challenge 1 can be defined as the human factor in safety management.

Based on the factor analysis theory [55], the above findings imply that human involvement in management routine has the greatest impact on safety at construction sites in China and is thus a key target for improvement.

3.4.2. Challenge 2: Equipment Factor. Factor 2 accounts for 14.324 of the total variance and is distilled from the following items:

(8) Personal protective equipment

(13) Proper installation and dismantling of plant and equipment

(14) Maintenance regime for all equipment and plants

(15) The reasonable choice of work equipment
Among the abovementioned items, 13-15 are concerned with mechanical equipment at the site, and item 8 is concerned with the personal protection of workers, such as gloves, helmets, and goggles, Thus, Challenge 2 can be defined as the equipment factor in safety management.

According to the statistics of the accident survey published by the National Bureau of Statistics, mechanical injuries are one of the five major types of accidents (Table 6), can incur substantial loss to both the construction company and the workers, and in extreme cases may even put workers in life-threatening situations. Therefore, mechanical equipment must be properly selected and used in accordance with standard operation procedures. To ensure safety, tower cranes and other machinery must be regularly and rigorously inspected, and workers must also receive and use necessary PPE.

3.4.3. Challenge 3: Environment Factor. Factor 3 accounts for $11.208 \%$ of the total variance and mainly covers the following items:

(22) Complexity of geology and hydrology

(23) Frequency of adverse weather

(24) Schedule and cost pressures

(32) Complexity of surrounding environment

These items reflect the influence of environment factors on safety management. Construction projects often have to deal with the adverse natural environment, and as the projects proceed, the project participants may create an artificial environment in which further challenges arise.

3.4.4. Challenge 4: Management Factor. Factor 4 entails the following items:

(4) The health and safety file

(5) Safety meeting

(9) Safety management commitment

(17) Safety regulation and plan enforcement

(18) Safety incentive and punishment

(21) Safety inspection and guidance

(25) Allocation of safety responsibility

All of the abovementioned come down to the management factors. A successful project requires good planning, organization, and coordination, and the influence of management on the workers and thus on project safety cannot be overlooked.

3.4.5. Challenge 5: Technical Factor. Factor 5 accounts for $7.684 \%$ of the total variance and involves the following items:

(19) Safety risk identification and analysis

(20) First aid and emergency preparedness

(29) The complexity type and technique of construction 
TABle 5: Rotated component matrix.

\begin{tabular}{|c|c|c|c|c|c|c|c|c|c|}
\hline \multirow{2}{*}{ Item } & \multicolumn{7}{|c|}{ Component } & \multirow{2}{*}{ Variance $(\%)$} & \multirow{2}{*}{ Extracted common factors } \\
\hline & 1 & 2 & 3 & 4 & 5 & 6 & 7 & & \\
\hline 2 & 0.81 & 0.095 & 0.098 & -0.012 & 0.071 & 0.099 & 0.254 & \multirow{11}{*}{32.986} & \multirow{11}{*}{ Human factor } \\
\hline 3 & 0.805 & 0.044 & -0.055 & 0.348 & 0.109 & -0.054 & 0.08 & & \\
\hline 31 & 0.746 & 0.045 & 0.208 & 0.186 & 0.058 & -0.266 & 0.211 & & \\
\hline 11 & 0.724 & 0.34 & -0.012 & 0.176 & 0.122 & 0.258 & -0.220 & & \\
\hline 1 & 0.692 & 0.138 & -0.018 & 0.04 & -0.105 & -0.158 & 0.452 & & \\
\hline 26 & 0.676 & 0.514 & -0.104 & 0.082 & 0.225 & 0.029 & -0.028 & & \\
\hline 6 & 0.654 & 0.128 & 0.18 & 0.14 & 0.247 & -0.056 & 0.21 & & \\
\hline 30 & 0.619 & 0.12 & 0.056 & 0.127 & 0.398 & 0.222 & -0.034 & & \\
\hline 12 & 0.613 & 0.38 & 0.01 & 0.522 & 0.056 & -0.022 & -0.058 & & \\
\hline 7 & 0.5 & 0.364 & 0.336 & 0.224 & 0.251 & -0.049 & -0.200 & & \\
\hline 10 & 0.449 & 0.339 & -0.222 & 0.351 & 0.309 & 0.164 & 0.1 & & \\
\hline 8 & 0.177 & 0.706 & -0.014 & 0.182 & 0.203 & 0.102 & 0.236 & \multirow{4}{*}{14.324} & \multirow{4}{*}{ Equipment factor } \\
\hline 13 & 0.201 & 0.696 & 0.016 & 0.079 & 0.059 & 0.179 & 0.309 & & \\
\hline 15 & 0.148 & 0.634 & 0.165 & 0.335 & 0.001 & -0.069 & 0.271 & & \\
\hline 14 & 0.207 & 0.628 & 0.336 & 0.191 & 0.115 & -0.043 & 0.009 & & \\
\hline 32 & -0.133 & 0.116 & 0.752 & 0.116 & 0.221 & -0.033 & 0.047 & \multirow{5}{*}{11.208} & \multirow{5}{*}{ Environment factor } \\
\hline 23 & 0.18 & 0.244 & 0.721 & 0.072 & -0.233 & 0.108 & 0.216 & & \\
\hline 22 & 0.068 & -0.155 & 0.681 & 0.287 & 0.092 & 0.141 & 0.022 & & \\
\hline 24 & 0.236 & 0.009 & 0.544 & 0.089 & 0.283 & -0.538 & -0.043 & & \\
\hline 25 & 0.048 & 0.17 & 0.437 & 0.28 & 0.342 & -0.371 & 0.328 & & \\
\hline 21 & 0.09 & 0.146 & 0.288 & 0.664 & 0.104 & 0.176 & 0.115 & \multirow{5}{*}{9.624} & \multirow{5}{*}{ Management factor } \\
\hline 18 & 0.259 & 0.154 & 0.184 & 0.648 & 0.203 & -0.040 & 0.036 & & \\
\hline 17 & 0.27 & 0.259 & 0.154 & 0.569 & -0.032 & 0.182 & 0.087 & & \\
\hline 9 & 0.485 & 0.081 & 0.041 & 0.513 & -0.050 & 0.333 & 0.159 & & \\
\hline 5 & 0.059 & 0.305 & 0.009 & 0.498 & 0.423 & -0.357 & 0.025 & & \\
\hline 4 & 0.333 & 0.238 & -0.038 & 0.078 & 0.688 & -0.030 & 0.083 & \multirow{4}{*}{7.684} & \multirow{4}{*}{ Technical factor } \\
\hline 20 & 0.224 & -0.057 & 0.167 & 0.281 & 0.652 & 0.373 & -0.043 & & \\
\hline 29 & -0.029 & 0.037 & 0.357 & -0.011 & 0.609 & -0.103 & 0.285 & & \\
\hline 19 & 0.396 & 0.322 & 0.155 & 0.046 & 0.538 & -0.215 & 0.197 & & \\
\hline 16 & -0.058 & 0.078 & 0.088 & 0.291 & 0.004 & 0.735 & 0.137 & \multirow{2}{*}{4.493} & \multirow{2}{*}{ I } \\
\hline 33 & 0.168 & 0.29 & 0.524 & -0.082 & 0.178 & 0.557 & -0.083 & & \\
\hline 27 & 0.082 & 0.207 & 0.113 & 0.156 & 0.18 & 0.133 & 0.735 & \multirow{3}{*}{2.864} & \multirow{3}{*}{ I } \\
\hline 34 & 0.43 & 0.259 & 0.093 & -0.049 & 0.129 & -0.103 & 0.633 & & \\
\hline 28 & 0.227 & 0.38 & 0.04 & 0.266 & 0.075 & 0.405 & 0.562 & & \\
\hline
\end{tabular}

TABLE 6: Breakdown of construction accidents in China (2008-2015).

\begin{tabular}{|c|c|c|c|c|c|c|c|c|}
\hline Accident types & 2009 & 2010 & 2011 & 2012 & 2013 & 2014 & 2015 & Mean \\
\hline Falling injuries (\%) & 51.90 & 47.37 & 53.31 & 52.77 & 46.15 & 54.57 & 53.17 & 51.32 \\
\hline Collapses (\%) & 13.74 & 14.83 & 14.60 & 13.76 & 19.23 & 11.75 & 13.36 & 14.47 \\
\hline Object strikes (\%) & 12.28 & 16.75 & 12.05 & 12.11 & 13.85 & 12.53 & 14.93 & 13.50 \\
\hline Crane machine accidents (\%) & 6.43 & 7.02 & 8.32 & 10.27 & 10.77 & 8.36 & 7.24 & 8.34 \\
\hline Electric shocks (\%) & 4.09 & 4.63 & 5.09 & 2.05 & 3.15 & 4.41 & 4.07 & 3.93 \\
\hline Others (\%) & 11.56 & 9.40 & 6.63 & 9.04 & 6.85 & 8.38 & 7.23 & 8.44 \\
\hline
\end{tabular}

The abovementioned items may be considered as technical factors. The technical staffs are in charge of selecting the most suitable technique and training the workers. Poor choice of the technique may undermine safety. In fact, two additional factors have also been extracted, the first from items 16 (proper handling of all equipment and plants) and 33 (welfare facilities), the second from items 27 (organizational capability of contractors), 28 (evaluation, selection, and control of subcontractors), and 34 (the numbers of modifying existing designs). Although they are statistically significant, they are not interpreted further because we do not see an explanation that corresponds to reality. For example, it is difficult to argue what kind of unique factor is in common within the items "proper handling of all equipment and plants" and "welfare facilities."

The Cronbach's alpha coefficient refers to the degree of consistency among different items within a certain dimension. It is a commonly used reliability index. In order to ensure the appropriateness of grouping the five extracted common factors, the consistency of each common factor was tested using the Cronbach's alpha coefficient. The results are 
TABLE 7: Results of Cronbach's alpha reliability test.

\begin{tabular}{lc}
\hline Extracted common factors & Cronbach's alpha coefficient \\
\hline Human factor & 0.774 \\
Equipment factor & 0.872 \\
Environment factor & 0.716 \\
Management factor & 0.762 \\
Technical factor & 0.814 \\
\hline
\end{tabular}

shown in Table 7. The alpha coefficient of each common factor is greater than the minimum expected value of 0.70 within the interval of $(0.716,0.872)$, indicating that each dimension has good internal consistency $[56,57]$.

\subsection{Weight of Importance for Factors and Ranking Consistency} between Participants. Estimation of the mean value shows that the top five most important items are the following:

(2) Safety behavior of workers

(1) Safety attitude of workers

(5) Safety meeting

(3) Safety training received by workers

(32) Complexity of surrounding environment

One-way ANOVA is detailed in Table 8 to show if there are significant differences among the influence of proprietor, consultant, designer, contractor, and supervisor on safety factors.

In Table 9, the Spearman rank correlation shows remarkable inconsistency between the proprietor and the designer. The contractor and the designer have a consistency at the level of 0.01 . The supervisor has a consistency level of 0.01 with all other entities, mainly because the supervisor coordinates them and resolves their conflicts.

3.6. Key Leverage Points. In Figure 4, we propose a model on construction safety according to our data. According to the contribution of 5 extracted common factors to the total variance in factor analysis (Table 5), the human factor presents the greatest challenge and is shown as the blue pillar in the middle. Note that the managers and the workers contribute differently to the human factor. This section looks for possible leverage points to fortify this blue pillar. We seek to identify elements within the human factor that could be reconditioned to foster safety management at construction sites and consequently bridge the "last mile."

The results of ANOVA show that there are some disagreements among the different entities on the main influencing factors of construction safety. At a significance threshold of 0.001 in ANOVA, the following five items were rated very differently by different respondents:

(7) Education level of workers

(17) Safety regulation and plan enforcement

(18) Safety incentive and punishment

(21) Safety inspection and guidance

(29) The complexity type and technique of construction
Designers gave low rating to item 7 , mainly because design and engineering are relatively independent stages in construction projects, and designers often assume by default their plan can be carried out by the workers without thinking about the background and capability of said workers. Item 18 received the highest rating from the proprietors. Most contractors claimed that, for an accident having no more than three deaths, the punishment is acceptable. Some contractors are even more willing to pay the fine than invest in safety, whereas the proprietors think that raising the fine can incentivize the contractors to improve safety. Item 21 received a low rating by all respondents except proprietors. Our interviews showed that although proprietors fully authorize supervisors regarding safety issues on the site, in reality, the supervisors have a low status. They are not readily welcomed by others and do not receive good cooperation, impairing their control over the projects. Both consultants and proprietors gave high ratings to item 17 and item 29 because they lack technical experience and are more concerned with the impact of engineering technique on safety.

The Spearman rank correlation analysis shows that proprietors and designers seriously disagree as to what are the top safety factors. They are both concerned with the workers' safety training and consider item 3 as the second most important safety factor, while the other four in their lists of top five were completely different. Designers are concerned with the following items:

(32) Complexity of surrounding environment

(22) Complexity of geology and hydrology

(23) Frequency of adverse weather

(2) Safety behavior of workers

For the proprietors, among these items only item 2 was ranked 9th while the others were considered much less important. Items 22, 23, and 32 focus on the complexity of the environment, which may heavily impact the realization of the design. The designers must test their plan under a variety of extremely adverse conditions to ensure safety and are thus highly concerned with the environmental factor.

Despite the differences of opinion on the abovementioned items, all respondents considered the items related to workers to be very important for safety. The safety behavior of workers (item 2), safety attitude of workers (item 1), safety training received by workers (item 3 ), experience and skills of workers (item 6), and education level of workers (item 7) were ranked the first, second, fourth, sixth, and tenth in the combined ranking from all 447 valid questionnaires. Therefore, considering the results of the Factor analysis and the Mean and ANOVA analysis synthetically, within the human factor, which itself is the number one challenge, the items related to workers are the key leverage points in safety management, including the safety behavior of workers (item 2), safety attitude of workers (item 1), safety training received by workers (item 3 ), experience and skills of workers (item 6), and education level of workers (item 7). The performance of the five 
TABLE 8: Mean and ANOVA analysis.

\begin{tabular}{|c|c|c|c|c|c|c|c|c|c|c|c|c|}
\hline \multirow{2}{*}{ Item } & \multicolumn{2}{|c|}{ Overall } & \multicolumn{2}{|c|}{ Proprietor } & \multicolumn{2}{|c|}{ Consultant } & \multicolumn{2}{|c|}{ Designer } & \multicolumn{2}{|c|}{ Contractor } & \multicolumn{2}{|c|}{ Supervisor } \\
\hline & Mean & Rank & Mean & Rank & Mean & Rank & Mean & Rank & Mean & Rank & Mean & Rank \\
\hline 2 & $4.2054^{*}$ & 1 & 3.86 & 9 & 3.84 & 9.5 & 4.04 & 4.5 & 4.21 & 1 & 4.23 & 1 \\
\hline 1 & $4.1027^{*}$ & 2.5 & 3.35 & 19 & 4.18 & 2 & 2.69 & 33 & 4.07 & 2 & 4.05 & 3.5 \\
\hline 5 & $4.1027^{*}$ & 2.5 & 3.76 & 10 & 4.20 & 1 & 3.86 & 8 & 3.93 & 7.5 & 4.12 & 2 \\
\hline 3 & $4.0622^{* *}$ & 4 & 4.17 & 2 & 3.96 & 7 & 4.22 & 2 & 4.05 & 3 & 4.01 & 6.5 \\
\hline 32 & $4.0351^{* *}$ & 5 & 3.34 & 20.5 & 3.18 & 25 & 4.24 & 1 & 3.79 & 9.5 & 4.03 & 5 \\
\hline 6 & 3.8876 & 6.5 & 3.28 & 24.5 & 3.56 & 19.5 & 3.57 & 17.5 & 3.96 & 4.5 & 4.05 & 3.5 \\
\hline 8 & 3.7976 & 6.5 & 2.96 & 28 & 3.69 & 14.5 & 3.75 & 11.5 & 3.93 & 7.5 & 3.88 & 9.5 \\
\hline 18 & $3.7865^{* *}$ & 8.5 & 4.20 & 1 & 4.16 & 3.5 & 3.59 & 16 & 3.69 & 14 & 3.77 & 12.5 \\
\hline 29 & $3.6865^{* *}$ & 8.5 & 4.07 & 4.5 & 3.74 & 11 & 3.64 & 14.5 & 3.66 & 15.5 & 3.28 & 15.5 \\
\hline 7 & $3.6595^{* *}$ & 10 & 3.70 & 11 & 3.16 & 26 & 3.57 & 17.5 & 3.96 & 4.5 & 4.01 & 6.5 \\
\hline 9 & $3.6459^{*}$ & 11.5 & 4.16 & 3 & 4.16 & 3.5 & 3.21 & 26.5 & 3.79 & 9.5 & 2.86 & 18.5 \\
\hline 11 & $3.6459^{*}$ & 11.5 & 3.45 & 16.5 & 3.84 & 9.5 & 3.75 & 11.5 & 2.69 & 32 & 3.88 & 9.5 \\
\hline 26 & $3.5819^{* *}$ & 13 & 3.28 & 24.5 & 3.76 & 10 & 3.44 & 20 & 3.66 & 15.5 & 3.89 & 8 \\
\hline 12 & 3.5749 & 14 & 3.69 & 12.5 & 3.71 & 12.5 & 3.27 & 22.5 & 3.77 & 11 & 3.59 & 14 \\
\hline 19 & 3.5703 & 15 & 3.95 & 7.5 & 3.56 & 19.5 & 3.78 & 9.5 & 3.75 & 12.5 & 2.99 & 17 \\
\hline 10 & 3.5568 & 16 & 3.95 & 7.5 & 3.56 & 19.5 & 3.66 & 13 & 3.75 & 12.5 & 2.86 & 18.5 \\
\hline 17 & $3.5027^{* *}$ & 17 & 3.96 & 6 & 3.23 & 23.5 & 2.99 & 30 & 3.48 & 19 & 3.79 & 11 \\
\hline 25 & 3.4892 & 18 & 3.34 & 20.5 & 4.07 & 5.5 & 3.38 & 21 & 3.44 & 21 & 2.86 & 18.5 \\
\hline 27 & 3.4849 & 19 & 3.43 & 18 & 3.09 & 27.5 & 3.48 & 19 & 3.65 & 17.5 & 2.78 & 23 \\
\hline 31 & $3.3811^{* *}$ & 20 & 2.91 & 29 & 3.09 & 27.5 & 3.64 & 14.5 & 3.28 & 23.5 & 3.77 & 12.5 \\
\hline 24 & 3.3676 & 21 & 3.32 & 22 & 3.69 & 14.5 & 3.88 & 6.5 & 3.95 & 6 & 2.77 & 24.5 \\
\hline 20 & 3.3270 & 22 & 2.90 & 30.5 & 3.69 & 14.5 & 3.88 & 6.5 & 3.45 & 20 & 2.69 & 26 \\
\hline 21 & $3.2459^{* *}$ & 23 & 4.07 & 4.5 & 2.97 & 29.5 & 3.22 & 25 & 3.32 & 22 & 2.86 & 18.5 \\
\hline 13 & 3.2323 & 24 & 2.80 & 32.5 & 2.76 & 34 & 3.26 & 24 & 3.65 & 17.5 & 3.28 & 15.5 \\
\hline 28 & 3.1514 & 25 & 2.53 & 34 & 4.07 & 5.5 & 3.21 & 26.5 & 3.19 & 25.5 & 2.77 & 24.5 \\
\hline 34 & 3.0378 & 26 & 3.69 & 12.5 & 3.69 & 14.5 & 3.78 & 9.5 & 2.89 & 29 & 2.67 & 27.5 \\
\hline 15 & $2.9943^{*}$ & 27 & 2.80 & 32.5 & 2.78 & 33 & 3.21 & 26.5 & 3.28 & 23.5 & 2.87 & 22 \\
\hline 4 & 2.9938 & 28 & 3.57 & 14 & 3.23 & 23.5 & 3.27 & 22.5 & 2.86 & 30.5 & 2.44 & 29 \\
\hline 16 & 2.9697 & 29 & 3.45 & 16.5 & 3.59 & 18 & 2.76 & 32 & 3.19 & 25.5 & 2.42 & 32 \\
\hline 30 & 2.9662 & 30 & 3.30 & 23 & 2.80 & 32 & 3.21 & 26.5 & 2.86 & 30.5 & 2.43 & 30.5 \\
\hline 22 & $2.9595^{* *}$ & 31 & 2.90 & 30.5 & 3.71 & 12.5 & 4.13 & 3 & 3.29 & 25.5 & 2.67 & 27.5 \\
\hline 14 & 2.9054 & 32 & 3.22 & 27 & 2.97 & 29.5 & 2.77 & 31 & 3.29 & 25.5 & 2.26 & 34 \\
\hline 23 & 2.7973 & 33 & 3.53 & 15 & 3.56 & 19.5 & 4.04 & 4.5 & 2.68 & 33 & 2.43 & 30.5 \\
\hline 33 & 2.527 & 34 & 3.23 & 26 & 3.89 & 8 & 2.44 & 34 & 2.47 & 34 & 2.28 & 33 \\
\hline
\end{tabular}

${ }^{*}$ Significant at the 0.05 level (two-tailed); ${ }^{* *}$ significant at the 0.01 level (two-tailed).

TABLE 9: Spearman rank correlation coefficients.

\begin{tabular}{|c|c|c|c|c|c|}
\hline & Proprietor & Consultant & Designer & Contractor & Supervisor \\
\hline \multirow{2}{*}{ Proprietor } & 1.000 & - & - & - & - \\
\hline & - & - & - & - & - \\
\hline \multirow{2}{*}{ Consultant } & $0.352^{*}$ & 1.000 & - & - & - \\
\hline & 0.026 & - & - & - & - \\
\hline \multirow{2}{*}{ Designer } & 0.232 & $0.352^{*}$ & 1.000 & - & - \\
\hline & 0.150 & 0.026 & - & - & - \\
\hline \multirow{2}{*}{ Contractor } & $0.395^{*}$ & $0.402^{*}$ & $0.479^{* *}$ & 1.000 & - \\
\hline & 0.012 & 0.010 & 0.002 & - & - \\
\hline \multirow{2}{*}{ Supervisor } & $0.450^{*}$ & $0.604^{* *}$ & $0.682^{* *}$ & $0.711^{* *}$ & 1.000 \\
\hline & 0.004 & 0.000 & 0.000 & 0.000 & - \\
\hline
\end{tabular}

*Significant at the 0.05 level (two-tailed); ${ }^{* *}$ significant at the 0.01 level (two-tailed).

items is closely related to the performance of construction safety management and is the key to solving the "last mile" problem. Since construction workers usually work in groups and teams, we propose a novel management framework in the next chapter to motivate the workers to safely react to spontaneous problems, thus bridging the "last mile."

\section{New Framework for Safety Management}

The construction site is a complex system, in which workers are the only entity that can adjust on its own. To lever the five leverage points identified above and amend the "last mile" problem in safety management, we propose a new organizational framework that can transform the top-down safety 


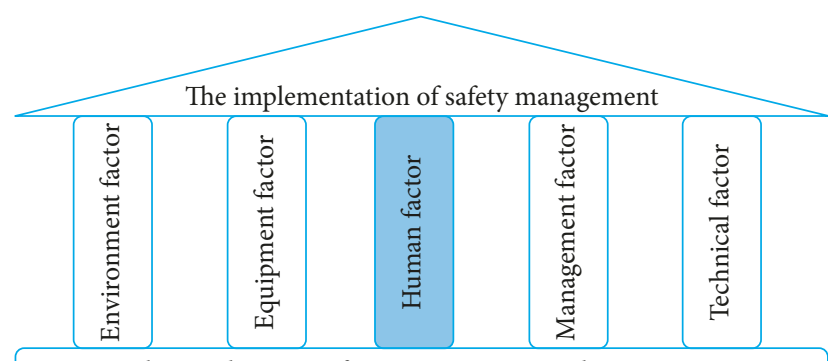

Improve the production safety management and supervision system

Figure 4: Safety factors and new framework for safety management.

management into bottom-up safety behavior. The core of the framework is to strengthen the guidance and supervision of the leaders above workers and the mutual guidance and supervision of the workers on construction sites, greatly improving the performance of the workers on the five leverage points.

4.1. Making Leaders Ubiquitous. At construction sites, safety issues can arise in any moment at any place, so external everpresent supervision and guidance is crucial for improving the safety behavior (item 1) and safety attitude (item 2) of workers. In other words, the leaders must be ubiquitous and always be prepared to solve problems quickly and efficiently. They must have the necessary technical skills, management ability, and a strong sense of responsibility.

As the organizational chart in Figure 5 shows, the few number of people in senior management positions make it impossible to serve the engineering and operation teams on a constant basis. The absence of leaders causes frequent accidents. To ensure safety management, leaders must be in their post at all times such that no worker would go to a duty without having the leader standing by on call.

4.2. Appointing Leaders. As mentioned above, a good leadership team is crucial for safety management on the construction site. Leaders should be appointed mainly based on technical skills, following the priority outlined below:

(1) The full-time safety management personnel in the project department is the leader of all working faces and public spaces.

(2) In the absence of (1), the registered or assigned administrative team leader or group leader for a particular working face or public space takes charge of all safety issues.

(3) In the absence of (2), the project manager should automatically become the leader when entering a particular working face or public space.

(4) When only workers are present, whoever entered the task area first should be the leader for that area.

(5) Among the workers who entered the task area at the same time, the most senior worker should be the leader.

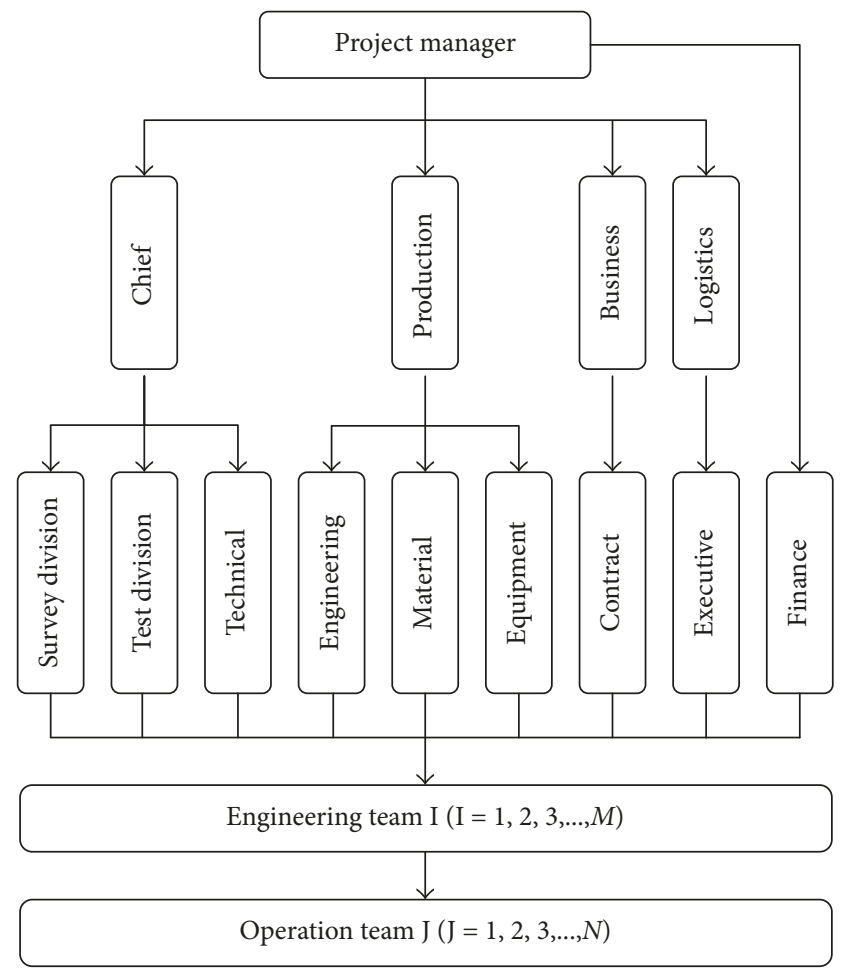

FIgURE 5: Typical organization structure for civil engineering projects in China.

In this way, the task area is always covered by a safety leader, helping eliminate accidents and minimize risks.

4.3. Pairing and Banding. As shown in Figure 3, worker's age, education, and work experience differ widely. Relatively speaking, workers with more experience and skills and higher education level have shown better performance in safety [55], which is consistent with the statistical analysis results in this paper. That is, safety training received by workers (item 3), experience and skills of workers (item 6), and education level of workers (item 7) are the key leverage points in safety management. Therefore, the mutual guidance and supervision of the different workers is also crucial for improving construction safety performance. Safety is not a one-man task, and all workers need to be covered by a teammate in situations where the person's own sight or ability may fall short. We thus propose that each day before work, workers should reaffirm who are their safety partners for the day and know for whom they must be keeping watch over. The pairing and banding scheme is described below in Table 10 .

\section{Case Study}

To test how effective the proposed framework is in enhancing safety, we invited two safety experts, both of whom participated in the design of the questionnaire and in drafting the new framework for safety management, to conduct a case study and audit the safety management of a project before and after introducing the new framework. 
TABle 10: The Pairing and Banding scheme.

Pairing assignment must be clearly understood and documented, either in writing or on a chart.

(2) Before starting work, the group leader should reaffirm or adjust the pairing assignment based on the attendance of the day and other personnel changes. In every task, the workers must make sure the pairing scheme takes effect and fulfill their responsibility.

(3) Partners should be paired in a complementary manner, for example, the junior with the senior, the old with the young, the male with the female, the strong with the less powerful, the hasty with the calm, and the bold with the diffident.
Banding

(1) Set up bands across pairs and workgroups with shared responsibility on safety during work. Two or more workers must coordinate during their task and ensure the safety of each other.

(2) Partners should constantly alert each other during work:

(i) Remind the partner of unsafe behaviors and situations to prevent accidents from happening. Maintain correspondence through calling and answering.

(ii) Mutual caring: allocate tasks reasonably and help each other during work.

(iii) Mutual supervision: make sure the partner strictly follows standards on wearing protective equipments and adheres to safety procedures and regulations.

(3) Whenever necessary, remind workers other than the designated partner of unsafe behaviors and situations to prevent accidents from happening. Maintain correspondence through calling and answering.
5.1. Studied Object. The case study was carried out at the Wuhan section of the Wuhan-Shenzhen highway project (Figure 6). This highway is designed to have six lanes in two ways with a roadbed width of $34.5 \mathrm{~m}$ and a speed limit of $120 \mathrm{~km} / \mathrm{h}$. Grand bridges are designed to be robust against three-hundred years of flooding, and all other bridges robust against one-hundred years of flooding. The connecting lines follow the Class II road standard and have a speed limit of $60 \mathrm{~km} / \mathrm{h}$ and a roadbed width of $12 \mathrm{~m}$. The entire section is designed to withstand Level I vehicle loading. It spans about $33 \mathrm{~km}$ and is subcontracted into five project sites. The engineering tasks mainly involved works on the roadbed, bridge, and protective devices. The five project sites were similar in both natural environment and engineering works, and thus they were suitable for the case study.

5.2. Rating the Construction Site for Each Attribute. The ideal rating method should allow the safety auditors to evaluate the attributes in an objective and straightforward manner, while minimizing the disparity between their evaluations of the same site at the same time [17]. Based on two expert interviews, four possible rating options were designed:

(i) Binary: all attributes receive a mark of either zero or one.

(ii) Continuous: all attributes receive an arbitrary value between zero and one.

(iii) Binary with N/A: all attributes receive a mark of zero or one, or be marked as not applicable.

(iv) Continuous with N/A: all attributes receive an arbitrary value between zero and one, or be marked as not applicable.

(1) Binary

In this rating scheme, " 0 " indicates negative and " 1 " indicates "positive." This is objective and straightforward and thus is the most commonly used rating scheme.

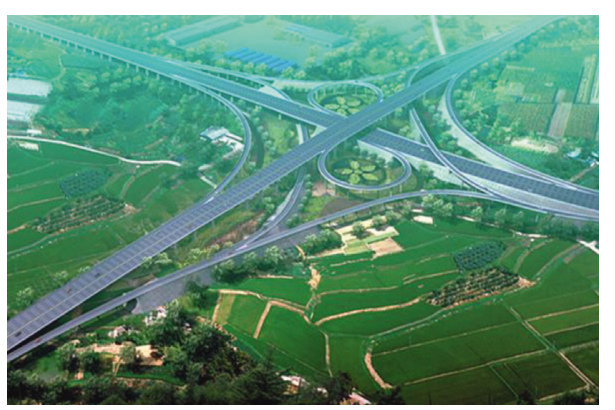

Figure 6: The Wuhan-Shenzhen highway project.

\section{(2) Continuous}

This rating scheme is normally applied to an attribute that is assessed based on a set of samples. The score is obtained through dividing the number of samples that meet a certain criteria by the total number of samples evaluated.

(3) $\mathrm{N} / \mathrm{A}$

An attribute is marked N/A only when it is irrelevant in the context of the given construction project.

After the attributes were marked, scores were calculated as follows:

$$
\text { Score }\left(S_{1}\right)=\text { weight }\left(w_{1}\right) \times \text { rate }\left(r_{1}\right) \text {, }
$$

where $S_{1}$ is the score for Attribute $1, w_{1}$ is the relative normalized weight of Attribute 1 , and $r_{1}$ is the auditor's assessment of Attribute 1 for a specific construction site. The attribute is the factor in the questionnaire.

The final audited safety management score was then summed as follows:

$$
\mathrm{CSI}_{\mathrm{i}}=\sum_{j=1}^{n} w_{j} r_{i j},
$$

where CSI is the total construction safety index of site $i, w_{j}$ is the weight of the $j$ th attribute, $j=1,2, \ldots, n$, and $r_{i j}$ is the rating of the $j$ th attribute at the site $i$. 


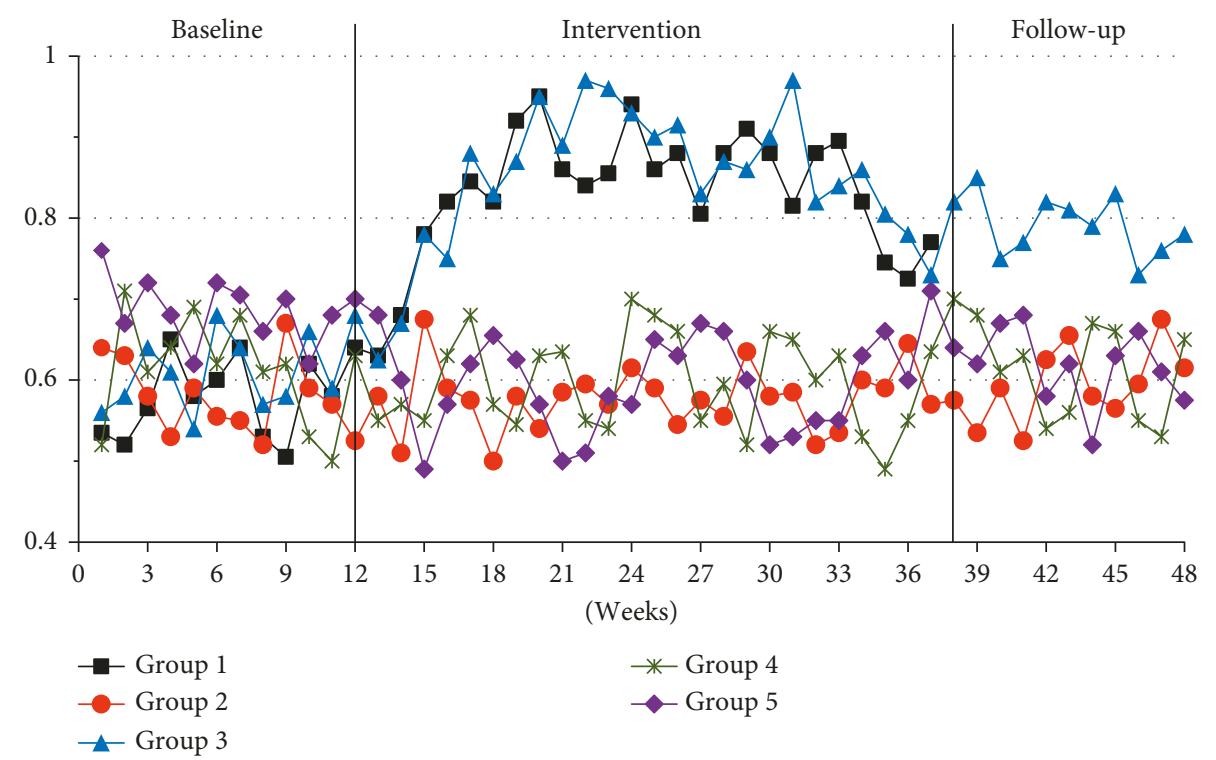

FIGURE 7: Safety evaluation records of two intervention and three control project sites.

5.3. Measurements. To determine how effective the proposed framework is in improving safety management, the five project sites were divided into two intervention groups and three control groups and observed for 48 weeks. Workers in the intervention groups were given coaching sessions by the members of the research team, and the two experts audited the safety management of all project sites every week. For groups 1 and 3 , the baseline evaluations of their safety performance were established over the initial 12 weeks. Intervention lasted 26 weeks for group 1, but only 23 weeks for group 3 because by then the construction had finished. Follow-up lasted 10 weeks. Specifically, the proposed management framework in this paper was introduced in detail to the top managers of two intervention groups firstly and received their strong support. Further, the framework was delivered and implemented to all staff on the construction site by ways of supervision meeting and preconstruction clarification. In accordance with the framework, each manager and worker was given a clear responsibility for safety management, and when the safety manager leaves the construction site for some reason, a relatively more experienced temporary safety manager must be appointed to ensure that leadership is always ubiquitous. Meanwhile, within every construction team, considering the gender, age, experience, and skills of each worker and other factors, each two workers were paired and bound according to the complementary principle. During the intervention, they were required to help and supervise each other in their works and be accountable for each other's safety. If one of them is rewarded or punished, the other one receives the same reward or punishment. In contrast, the control group maintains the original safety management framework. The two experts made surprise visits to the sites every week without a predictable schedule. The first expert was responsible for auditing groups 1 and 2, and the second expert for groups 3, 4, and 5.

5.4. Safety Outcomes from Trial Audits. Figure 7 shows the ratings of the five projects sites before and after the intervention. In the three control groups (groups 2, 4, and 5), there were no significant changes, and their CSI scores remained fairly constant over the entire 48 weeks at an average of $0.58,0.61$, and 0.62 . For the intervention group 1 , the CSI scores went from a baseline of 0.58 to 0.84 during the intervention and to 0.81 at follow-up. For intervention group 3 , the CSI scores in the three stages were $0.62,0.88$, and 0.79 , respectively. For the two intervention groups, CSI scores increased significantly during follow-up-both individually (39.1\% and $28.4 \%$ increase) and when combined (33.8\%). Therefore, the proposed framework proved to evidently strengthen safety management at construction sites and solve the "last mile" problem.

\section{Conclusions and Future Work}

In this work, we reviewed and discussed the main factors affecting construction safety from the macro-, meso-, and microlevels. We then defined the "last mile" problem. Subsequently, the human factor was identified to be the leverage point of construction safety management based on a questionnaire survey and statistical analysis, which helps to deepen the understanding of the accident rules on construction sites in China. Further, we proposed a new framework that requires ubiquitous presence of leaders at all times and puts workers into pairs and bands to strengthen safety. The proposed framework was tested in five sections of the Wuhan-Shenzhen highway project and was found effective in enhancing safety management and thus solving the "last mile" problem.

Due to time and cost constraints, the questionnaire survey could not be conducted at a still larger scale. Massive data were obtained through one single survey to which numerous workers provided their responses during their spare time working. This workload made data collection laborious and expensive, although it was indeed essential to secure a reliable input dataset for the sound modeling and analysis of safety performance. In the future, we plan to 
adopt automatic data acquisition based on the on-line Group Decision System (GDS) to collect related data from international subjects and then analyze the difference in safety cultures and practices across countries and among construction enterprises around the globe.

\section{Conflicts of Interest}

The authors declare that they have no conflicts of interest.

\section{Acknowledgments}

The project was financed by the National Key R\&D Program of China (2017YFC0805500). The authors thank the workers, foremen, and safety coordinators of the main contractors for their participation. The authors also wish to thank Engineer Peilun $\mathrm{Tu}$ for assistance in gathering field data.

\section{References}

[1] O. A. Jannadi and M. S. Bu-Khamsin, "Safety factors considered by industrial contractors in Saudi Arabia," Building and Environment, vol. 37, no. 5, pp. 539-547, 2002.

[2] D. Fang and H. Wu, "Development of a Safety Culture Interaction (SCI) model for construction projects," Safety Science, vol. 57, pp. 138-149, 2013.

[3] H. Lee, K.-P. Lee, M. Park, Y. Baek, and S. H. Lee, "RFIDbased real-time locating system for construction safety management," Journal of Computing in Civil Engineering, vol. 26, no. 3, pp. 366-377, 2012.

[4] W. Liu, T. Zhao, W. Zhou, and J. Tang, "Safety risk factors of metro tunnel construction in China: an integrated study with EFA and SEM," Safety Science, vol. 105, pp. 98-113, 2018.

[5] L. Ding, L. Zhang, X. Wu, M. J. Skibniewski, and Y. Qunzhou, "Safety management in tunnel construction: case study of Wuhan metro construction in China," Safety Science, vol. 62, no. 2, pp. 8-15, 2014.

[6] R. M. Choudhry and D. Fang, "Why operatives engage in unsafe work behavior: investigating factors on construction sites," Safety Science, vol. 46, no. 4, pp. 566-584, 2008.

[7] Z. Ismail, S. Doostdar, and Z. Harun, "Factors influencing the implementation of a safety management system for construction sites," Safety Science, vol. 50, no. 3, pp. 418-423, 2012.

[8] Law of the People's Republic of China on production safety," in Proceedings of the Standing Committee of the Ninth People's Congress of the People's Republic of China, Beijing, China, June 2002.

[9] State Council of the People's Republic of China, The Administrative Regulations on the Work Safety of Construction Projects, State Council of the People's Republic of China, Beijing, China, 2004.

[10] GB/T 28001-2011, Occupational Health and Safety Management Systems-Requirements, SAOT, Beijing, China, 2012.

[11] D. Meadows, "Places to intervene in a system," Whole Earth, vol. 91, pp. 78-84, 1997.

[12] L. Wang, B. Nie, and J. Zhang, "Study on coal mine macro, meso and micro safety management system," Perspectives in Science, vol. 7, pp. 266-271, 2016.

[13] T. Niskanen, K. Louhelainen, and M. L. Hirvonen, "A systems thinking approach of occupational safety and health applied in the micro-, meso- and macro-levels: a Finnish survey," Safety Science, vol. 82, pp. 212-227, 2016.
[14] S. Rowlinson, Hong Kong Construction-Site Safety Management, Sweet \& Maxwell, London, UK, 1997.

[15] M. Laberge and E. Ledoux, "Occupational health and safety issues affecting young workers: a literature review," Work, vol. 39, no. 3, pp. 215-232, 2011.

[16] D. P. Fang, F. Xie, X. Y. Huang, and H. Li, "Factor analysisbased studies on construction workplace safety management in China," International Journal of Project Management, vol. 22, no. 1, pp. 43-49, 2004.

[17] E. A. L. Teo and F. Y. Y. Ling, "Developing a model to measure the effectiveness of safety management systems of construction sites," Building and Environment, vol. 41, no. 11, pp. 1584-1592, 2006.

[18] C. M. Tam and I. W. H. Fung, "Effectiveness of safety management strategies on safety performance in Hong Kong," Construction Management and Economics, vol. 16, no. 1, pp. 49-55, 1998.

[19] N. A. Kartam, I. Flood, and P. Koushki, "Construction safety in Kuwait: issues, procedures, problems, and recommendations," Safety Science, vol. 36, no. 3, pp. 163-184, 2000.

[20] L. Koskela, An Exploration Towards a Production Theory and its Application to Construction, Vtt Publications, Espoo, Finland, 2000.

[21] K. C. Terwel and S. J. T. Jansen, "Critical factors for structural safety in the design and construction phase," Journal of Performance of Constructed Facilities, vol. 29, no. 3, p. 040140683 , 2015.

[22] S. Yule, Senior Management Influence on Safety in the UK and US Energy Sectors, Ph.D. thesis, University of Aberdeen, Aberdeen, UK, 2003.

[23] R. A. Choudhry, D. Fang, and S. Mohamed, "The nature of safety culture: a survey of the state-of-the-art," Safety Science, vol. 45, no. 10, pp. 993-1012, 2007.

[24] T. Chinda, "Structural equation modelling of result factors of construction safety culture," in Proceedings of the International Conference on Construction and Real Estate Management, Brisbane, Australia, December 2010.

[25] K. R. Molenaar, J. Park, and S. Washington, "Framework for measuring corporate safety culture and its impact on construction safety performance," Journal of Construction Engineering and Management, vol. 135, no. 6, pp. 488-496, 2009.

[26] D. P. Gilkey, C. L. D. Puerto, T. Keefe et al., "Comparative analysis of safety culture perceptions among homesafe managers and workers in residential construction," Journal of Construction Engineering and Management, vol. 138, no. 9, pp. 1044-1052, 2012.

[27] D. Zohar, "Safety climate in industrial organizations: theoretical and applied implications," Journal of Applied Psychology, vol. 65, no. 1, pp. 96-102, 1980.

[28] M. A. Griffin and A. Neal, "Perceptions of safety at work: a framework for linking safety climate to safety performance, knowledge, and motivation," Journal of Occupational Health Psychology, vol. 5, no. 3, pp. 347-358, 2000.

[29] S. Mohamed, "Safety climate in construction site environments," Journal of Construction Engineering and Management, vol. 128, no. 5, pp. 375-384, 2002.

[30] M. D. Cooper and R. A. Phillips, "Exploratory analysis of the safety climate and safety behavior relationship," Journal of Safety Research, vol. 35, no. 5, pp. 497-512, 2004.

[31] D. Zohar, "Thirty years of safety climate research: reflections and future directions," Accident Analysis and Prevention, vol. 42, no. 5, pp. 1517-1522, 2010.

[32] P. Kinesa, J. Lappalainen, K. L. Mikkelsen et al., "Nordic safety climate questionnaire (NOSACQ-50): a new tool for diagnosing 
occupational safety climate," International Journal of Industrial Ergonomics, vol. 41, no. 6, pp. 634-646, 2011.

[33] D. P. Fang, Y. Chen, and L. Wong, "Safety climate in construction industry: a case study in Hong Kong," Journal of Construction Engineering and Management, vol. 132, no. 6, pp. 573-584, 2006.

[34] S. Lin, W.-J. Tang, J.-Y. Miao, Z.-M. Wang, and P.-X. Wang, "Safety climate measurement at workplace in China: a validity and reliability assessment," Safety Science, vol. 46, no. 7, pp. 1037-1046, 2008.

[35] R. M. Choudhry, D. Fang, and H. Lingard, "Measuring safety climate of a construction company," Journal of Construction Engineering and Management, vol. 135, no. 9, pp. 890-899, 2009.

[36] B. B. Stoilkovska, V. Z. Pancovska, and G. Mijoski, "Relationship of safety climate perceptions and job satisfaction among employees in the construction industry: the moderating role of age," International Journal of Occupational Safety and Ergonomics, vol. 21, no. 4, pp. 440-447, 2015.

[37] P. C. Liao, G. Lei, J. W. Xue et al., "Influence of personorganizational fit on construction safety climate," Journal of Management in Engineering, vol. 31, no. 4, p. 04014049, 2013.

[38] X. Wu, Q. Liu, L. Zhang, M. J. Skibniewski, and Y. Wang, "Prospective safety performance evaluation on construction sites," Accident Analysis \& Prevention, vol. 78, pp. 58-72, 2015.

[39] D. A. Wiegmann, H. Zhang, T. von Thaden, G. Sharma, and A. Mitchell, "A synthesis of safety culture and safety climate research,” Tech. Rep. ARL-02-03/FAA-02-2, University of Illinois at Urbana-Champaign, Champaign, IL, USA, 2002.

[40] M. Martinez-Corcoles, F. Gracia, I. Tomas, and J. M. Peiro, "Leadership and employees' perceived safety behaviors in a nuclear power plant: a structural equation model," Safety Science, vol. 49, no. 8-9, pp. 1118-1129, 2011.

[41] R. Flin, K. Mearns, P. O'connor, and R. Bryden, "Measuring safety climate: identifying the common features," Safety Science, vol. 34, no. 1-3, pp. 177-192, 2000.

[42] S. Mohamed, T. H. Ali, and W. Y. V. Tam, "National culture and safe work behaviour of construction workers in Pakistan," Safety Science, vol. 47, no. 1, pp. 29-35, 2009.

[43] Q. Zhou, D. Fang, and X. Wang, "A method to identify strategies for the improvement of human safety behavior by considering safety climate and personal experience," Safety Science, vol. 46, no. 10, pp. 1406-1419, 2008.

[44] T. A. Saurin and L. B. de Macedo Guimaraes, "Ergonomic assessment of suspended scaffolds," International Journal of Industrial ergonomics, vol. 38, no. 2, pp. 238-246, 2008.

[45] L. Zheng, H. Xiang, X. Song, and Z. Wang, "Nonfatal unintentional injuries and related factors among male construction workers in central China," American Journal of Industrial Medicine, vol. 53, no. 6, pp. 588-595, 2010.

[46] B. Jitwasinkul and B. H. W. Hadikusumo, "Identification of important organisational factors influencing safety work behaviours in construction projects," Journal of Civil Engineering and Management, vol. 17, no. 4, pp. 520-528, 2011.

[47] M. Leung, Y. Chan, and K. Yuen, "Impacts of stressors and stress on the injury incidents of construction workers in Hong Kong," Journal of Construction Engineering and Management, vol. 136, no. 10, pp. 1093-1103, 2010.

[48] Y. H. Hung, T. S. Jackson, and W. Winchester, "Use of attitude congruence to identify safety interventions for small residential builders," Construction Management and Economics, vol. 29, no. 2, pp. 113-130, 2011.
[49] S. Chi, S. Han, and D. Y. Kim, "Relationship between unsafe working conditions and workers' behavior and impact of working conditions on injury severity in US construction industry," Journal of Construction Engineering and Management, vol. 139, no. 7, pp. 826-838, 2013.

[50] B. M. Mattila and M. Hyttinen, "Effective supervisory behavior and safety at the building site," International Journal of Industrial Ergonomics, vol. 13, no. 2, pp. 85-93, 2010.

[51] E. Teo, F. Ling, and A. Chong, "Framework for project managers to manage construction safety," International Journal of Project Management, vol. 23, no. 4, pp. 329-341, 2005.

[52] C. Lu and K. Shang, "An empirical investigation of safety climate in container terminal operators," Journal of Safety Research, vol. 36, no. 3, pp. 297-308, 2005.

[53] J. Wang and H. Yuan, "Factors affecting contractors' risk attitudes in construction projects: case study from China," International Journal of Project Management, vol. 29, no. 2, pp. 209-219, 2011.

[54] J. F. Hair, Multivariate Data Analysis with Readings, Macmillan, New York, NY, USA, 1987.

[55] J. O. Kim and C. W. Mueller, Factor Analysis: Statistical Methods and Practical Issues, Sage Pub. Inc., Thousand Oaks, CA, USA, 1978.

[56] E. Jorgensen, R. K. Sokas, L. Nickels, W. Gao, and J. L. Gittleman, "An English/Spanish safety climate scale for construction workers," American Journal of Industrial Medicine, vol. 50, no. 6, pp. 438-442, 2007.

[57] M. N. Vinodkumar and M. Bhasi, "Safety climate factors and its relationship with accidents and personal attributes in the chemical industry," Safety Science, vol. 47, no. 5, pp. 659-667, 2009. 


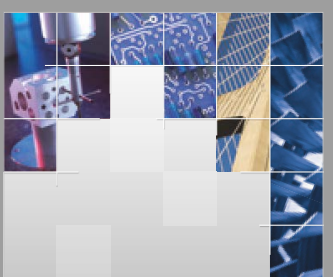

\section{Enfincering}
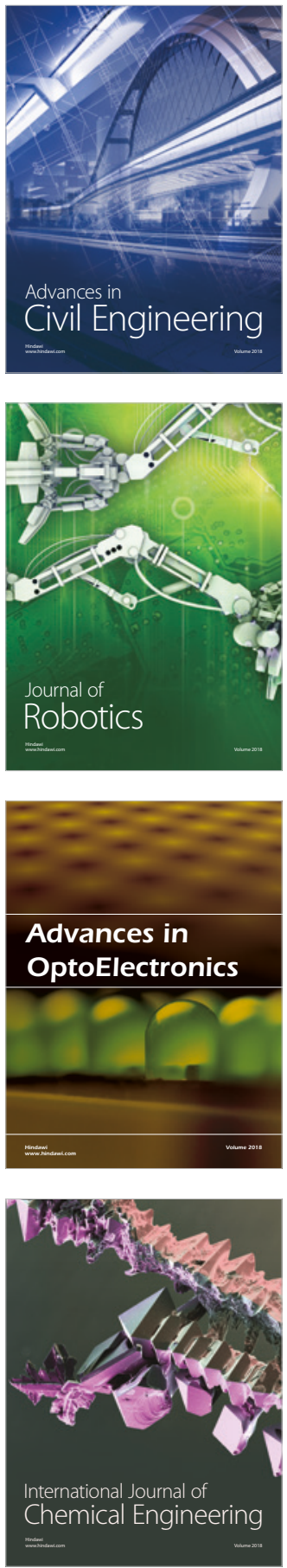

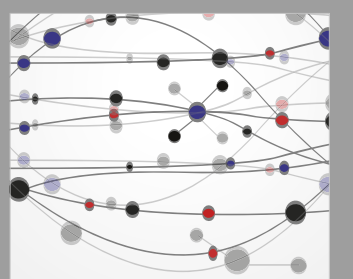

\section{Rotating \\ Machinery}

The Scientific World Journal

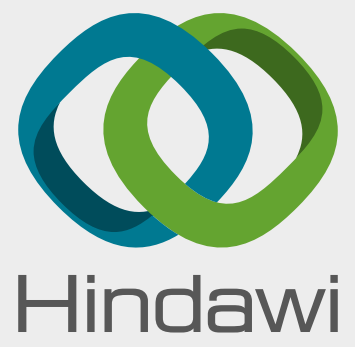

Submit your manuscripts at

www.hindawi.com
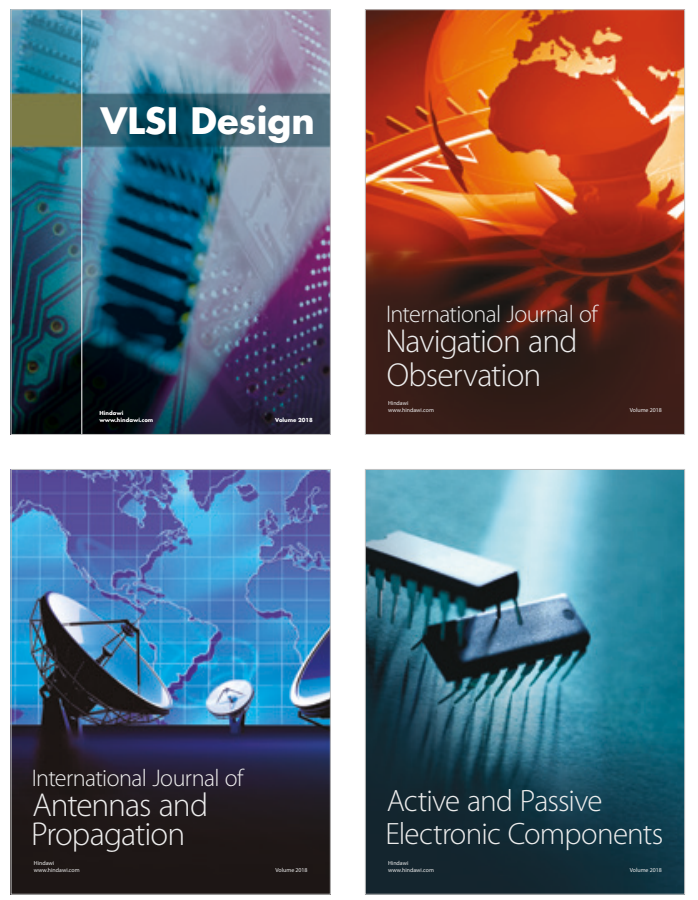
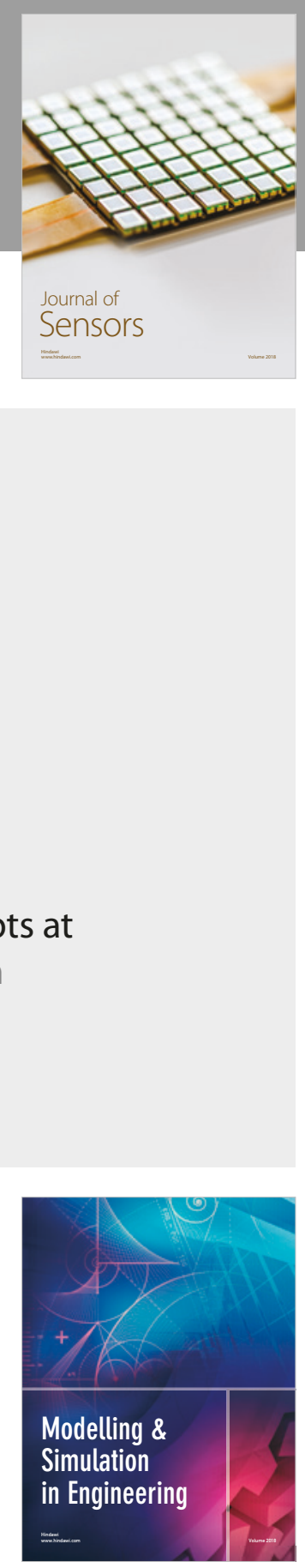

\section{Advances \\ Multimedia}
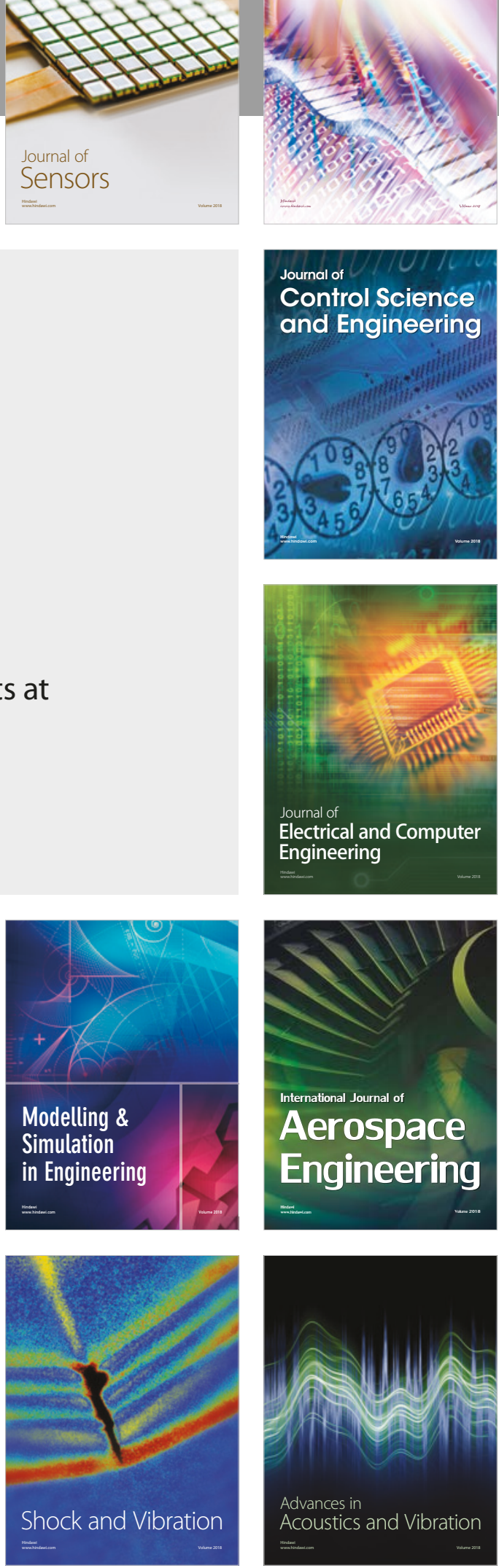